Flávia Manuella Uchôa-de-Oliveira ${ }^{\mathrm{a}, \mathrm{b}}$ (iD) https://orcid.org/0000-0002-6847-8436

a Universidade Nove de Julho (Uninove), Psicologia. São Paulo, SP, Brasil

b Universidade de São Paulo (USP), Laboratório de Estudos e Pesquisas sobre Trabalho, Movimentos Sociais e Políticas Sociais. São Paulo, SP, Brasil

Contato:

Flávia Manuella Uchôa-de-Oliveira

E-mail:

flavia.muo@gmail.com

A autora informa que este trabalho não é baseado em tese ou dissertação e que não foi apresentado em evento científico.

A autora declara que o estudo não foi subsidiado e que não há conflitos de interesses.

\section{Saúde do trabalhador e o aprofundamento da uberização do trabalho em tempos de pandemia}

\author{
Workers' health and the consequences of work \\ uberization in pandemic times
}

\section{Resumo}

Introdução: este ensaio é um esforço de compreensão do nosso presente, no qual emerge uma crise sanitária sem precedentes, ocasionada pelo surgimento do novo coronavírus, levando grande parte dos trabalhadores uberizados a realizar suas atividades como prestadores de "serviços essenciais" para a manutenção das regras de distanciamento social. Objetivo: estabelecer uma perspectiva sobre os possíveis aprofundamentos da uberização do trabalho durante e após a pandemia. Métodos: para estabelecer essa perspectiva, partimos da psicologia social do trabalho e da noção de polimorfia do trabalho, isto é, das várias e diferentes formas de trabalho que se apresentam em nosso contexto. Discussão: apresentamos a caracterização e definição da uberização do trabalho como uma nova maneira de gerir, organizar e controlar o trabalho, focalizando especialmente o Brasil e a América Latina. Indicamos que, entre os possíveis aprofundamentos da uberização do trabalho no contexto pós-pandemia, está a desregulação das relações de trabalho em nosso país, com a regressão da legislação trabalhista tendo por justificativa o liberalismo econômico. Conclusão: dentre os aspectos a serem considerados para pensarmos a saúde dos trabalhadores uberizados no pós-pandemia, está o exacerbado controle do trabalho e a necessidade de aproximação daqueles que estudam a saúde do trabalhador dos movimentos coletivos de trabalhadores uberizados.

Palavras-chave: uberização do trabalho; pandemia; psicologia social do trabalho; saúde do trabalhador.

\begin{abstract}
Introduction: the emergence of an unprecedented health crisis, caused by the New Coronavirus, leads "uberized" workers to become "essential service providers" helping the population comply with the social distancing rules. Objective: to verify the potential consequences of work uberization during and after the pandemic. Methods: we used social psychology of work and the notion of "work polymorphism", that is, the various forms that working assumes in our current context. Discussion: we characterize work uberization as a new way of managing, organizing and controlling work, focused on the Brazilian and Latin American scenarios. We argue that the precariousness of labor relations, arising from economic liberalism, could deepen the uberization of work in the post-pandemic context. Conclusion: among the aspects to be considered when pondering about workers' health in pandemic and post-pandemic is the excessive control of work and the need to shorten the distance between those who study workers' health and the collective movements of uberized workers.
\end{abstract}

Keywords: uberization of work; pandemic; social psychology of work; occupational health. 


\section{Introdução}

Este ensaio é um esforço de compreensão do momento atual, em que o trabalho uberizado ${ }^{1}$ ganha aprofundamento no desenrolar de uma crise sem precedentes, ocasionada pela pandemia do novo coronavírus. Nosso objetivo é estabelecer uma perspectiva para este tipo de trabalho no pós-pandemia, considerando os impactos que já podem ser observados. Partimos da psicologia social do trabalho para empreender este esforço, especificamente, da noção de polimorfia do trabalho.

No contexto brasileiro, o trabalho toma corpo em muitas e variadas formas, tantas e tão conectadas, que Leny Sato nos oferece a imagem do caleidoscópio para pensá-las. A autora estabelece não apenas um recurso imagético para a análise do trabalho, mas também um nome para esta miríade de formas interconectadas: a polimorfia do trabalho².

Para Sato, o trabalho em nosso país é caracterizado pelo trânsito constante dos trabalhadores entre as áreas centrais e periféricas do trabalho. A polimorfia do trabalho, como pensada por ela, busca trazer complexidade às análises do trabalho, principalmente no contexto brasileiro em que os trabalhadores estão inseridos em várias atividades ao mesmo tempo, transitando entre mercados e criando trabalho. Esta noção torna-se uma ferramenta analítica que considera uma perspectiva dinâmica e histórica do trabalho, levando em conta as transformações que as várias formas de trabalhar sofrem ao longo do tempo ${ }^{2}$.

Podemos adicionar a esta perspectiva um outro elemento: a precarização que constitui a polimorfia do trabalho no contexto brasileiro. Esse seria o "movimento em direção ao precário"3, nas várias formas de criar trabalho das trabalhadoras e dos trabalhadores brasileiros. Essa precarização vem na inércia da própria "formação do mercado de trabalho" em nosso país 4 . O que quer dizer que a precarização constituinte da polimorfia do trabalho, e a massa de trabalhadores que nela transita, vai sendo reorganizada e movimentada no curso histórico.

Esta precarização está posta, por exemplo, nos anos pós-1888, na Constituição liberal de 1891, e nos trinta anos do laissez-faire brasileiro, em que trabalhadores e patrões eram vistos como sendo agentes "livres" e "iguais" perante a Lei. E, por isso, qualquer movimento coletivo e de resistência desses trabalhadores era visto como ilegal. Os anos de 1930 trouxeram a Era Vargas, com a qual se inicia um processo de reorganização das massas de trabalhadores por outros caminhos. Ao invés de somente negar ou tornar ilegal a possibilidade de organização e de luta pelo acesso à cidadania, a Era Vargas tornou possível regular os movimentos dos trabalhadores e definir as regras de acesso ao emprego e à cidadania ${ }^{5}$.

A carteira de trabalho tornou-se o registro cívico, e a "cidadania regulada" 6 pelo emprego surgiu como uma forma de reorganizar: incluindo, excluindo, regulando e dispondo da massa de trabalhadores. A referência do emprego como a chave de acesso à cidadania é mantida ao longo dos anos de ditadura civil-militar, conservada no pensamento econômico desenvolvimentista daquela época. Mas o emprego não resistirá à reestruturação produtiva dos meados da década de 1970 e aos ventos políticos que sopraram do Norte no início da década de 1980.

Assim como a era Vargas, a era neoliberal redefine a polimorfia do trabalho em nosso país e reorganiza a precarização que a constitui. A partir do final dos anos de 1980, o mundo sem emprego é apresentado aos trabalhadores brasileiros ${ }^{7}$. Assim como explicam Conserva e Araújo ${ }^{8}$, "a crise dos modelos nacional e desenvolvimentista em geral legou enormes bolsões de informalidade e miséria metropolitana, avolumando estruturalmente o fenômeno da informalidade e da exclusão".

Isto quer dizer que a este avolumado de trabalhadores foram impostas, aos poucos, outras formas de criar trabalho e, ao fim e ao cabo, de "se virar". Ao longo dos últimos trinta anos, a integração individual no mercado de trabalho passa ser a forma de organização predominante. Para sua inserção, o trabalhador deve aprender a se autogerir, tornar-se empregável, investindo em si mesmo. Deve, especialmente, aprender a ser um empreendedor: um indivíduo em constante formação que toma para si todos os riscos de seu trabalho.

Na atualidade, é possível afirmar que a inserção individual no mercado de trabalho tem seu ápice no que vem sendo nomeado de "uberização do trabalho" por vários autores ao redor do mundo.

Ludmila Costhek Abílio ${ }^{1}$, uma das principais referências sobre o tema no Brasil, indica que a uberização do trabalho pode ser definida como uma nova maneira de gerir, organizar e controlar o trabalho que se afirma como tendência global. A desindustrialização e, por conseguinte, o boom do setor de serviços abriu espaço para uma nova forma de organização, cujo impacto nas relações de trabalho e na economia mundial vem sendo amplamente documentado ${ }^{9}$.

Apesar de referir-se à Uber pela força que esta empresa ganhou na economia, a uberização está atrelada à mediação feita por diversas plataformas digitais que conectam prestadores de serviço a consumidores, articulando os dados gerados por ambas as partes nesta interação. Há, nesse sentido, um novo tipo de gerenciamento do trabalho, no qual as 
informações de tempos e movimentos dos trabalhadores podem ser registradas em detalhes por meio dos algoritmos desenhados pela plataforma. A avaliação dos consumidores também será fonte de dados para este controle do tempo e do movimento e, igualmente, para certificar a qualidade do serviço realizado. Na uberização, a multidão de consumidores gera informações para o controle e para a avaliação da multidão de trabalhadores.

Como complemento ou como fonte principal de renda, as plataformas digitais fornecem a possibilidade de dispersar o trabalho, ao mesmo tempo que mantêm o controle sobre ele. Entre o novo e o arcaico, a uberização atualiza as formas de controle e as desigualdades sociais. Pode ser compreendida como um "resultado" do que se acumulou há ao menos cinco décadas: cadeias de produção fragmentadas com massivos processos de terceirização e de subcontratações, além da progressiva perda de direitos sociais e trabalhistas ${ }^{10}$.

É dessa forma que a uberização do trabalho articula o novo e o antigo na gestão da polimorfia do trabalho. O novo está posto na tecnologia empregada pelas "empresas-aplicativo" para reorganizar as já antigas formas de criar trabalho e de se inserir economicamente dos trabalhadores brasileiros. Os bicos, o freelance, as "ôias", o trabalho "por conta" e o "se virar" são organizados agora pela tecnologia que media e controla as interações entre "consumidores" e "prestadores de serviços".

Trata-se de uma novidade tecnológica que organiza a "viração", tão característica do mercado de trabalho brasileiro e latino-americano. No Sul global, o emprego não chegou a ser a norma e, para a maioria da "população que vive do trabalho" 11 , o emprego sempre foi complementado por outras atividades de trabalho, em paralelo e interpostas. É neste sentido que a uberização do trabalho organiza a informalização e aprofunda a precarização do trabalho; organiza a massa de trabalhadores que não encontram emprego e tem de se inserir no mercado informal; aprofunda a precarização do trabalho no repasse de todo e qualquer custo do trabalho para o trabalhador, sem que ele possa negociar suas condições de trabalho e o valor de seu serviço ou produto.

Ademais, a uberização do trabalho aprofunda desigualdades ao passo que dissemina a precarização por dentro do emprego. Isto é, repete-se a cadeia de vulnerabilidade e desigualdade social, mas têm-se perdas de garantias e direitos mesmo entre aqueles que tinham algum nível de proteção social. A precarização e a informalização, típicas da uberização, são espelhadas em um "movimento global" de eliminação de direitos, garantias e segurança, aspectos que estavam ligados diretamente ao emprego e ao mercado formal de trabalho ${ }^{12}$.
É possível afirmar que a uberização é resultado do receituário neoliberal baseado na flexibilização, na desregulação e na privatização. O discurso do liberalismo econômico, a partir da relação entre agentes livres e iguais que com as suas interações regulam o mercado, é atualizado nestas novas formas de organização do trabalho. Todavia, ao mesmo tempo que este discurso é recolocado, ele perde sua força quando confrontado com a realidade de controle do trabalho e da subsunção do trabalhador às plataformas digitais ${ }^{13}$.

A saber, os trabalhadores uberizados não negociam o preço de seu trabalho pois recebem seus rendimentos de acordo com tarifas determinadas pela plataforma; também não têm acesso às regras para distribuição das demandas entre os trabalhadores, nem sobre como são feitas as médias de suas avaliações. Além disso, os trabalhadores podem ser desligados do aplicativo a qualquer momento sem que seja necessária nenhuma justificativa ou explicação por parte da plataforma, trazendo a possibilidade real de que de um dia para o outro o trabalhador perca sua fonte de renda. Outro ponto está no impedimento de negociação sobre o trabalho e da falta de transparência sobre as regras que determinam a distribuição da demanda, há o repasse de todos os custos operacionais do trabalho para os trabalhadores, o que diminui ainda mais o valor total do serviço prestado.

\section{Dimensão e delineamento do problema}

Por este cenário de subsunção real dos trabalhadores ao controle destas empresas-aplicativo, movimentos coletivos de trabalhadores uberizados têm se espalhado mundo afora. A partir de 2015, estes movimentos ganharam força, renovando o sentido da greve: utilizando a paralisação total ou parcial dos serviços, trazendo a novidade de uma organização informal e descentralizada. Naquele ano, na França, as paralisações dos motoristas da Uber reclamaram a diminuição da taxa do aplicativo e protestaram realizando "operações tartarugas" no serviço ${ }^{14}$.

Em 2016, os trabalhadores uberizados se juntaram a movimentos mais amplos - por exemplo, o chamado de "Fight for \$15", que exigia um rendimento mínimo por hora para os trabalhadores nos Estados Unidos. Em 2017, na Espanha, entregadores por aplicativos formaram associações para exigir a garantia de direitos, tendo relação direta com a União Geral do Trabalhadores (UGT). Dessa relação desenvolveu-se um portal para atendimento de reclamações dos trabalhadores uberizados ${ }^{15}$. Ao longo do ano de 2019 e do primeiro semestre de 2020, manifestações da categoria se espalharam na América Latina e em outros países da Europa ${ }^{16}$. 
No Brasil, estes movimentos, localizados primeiramente na região Sudeste, estão tomando forma em outras regiões. Nas paralisações do último abril, foi reportado no World Socialist Website que "[...] centenas de entregadores em Teresina, Piauí, no Nordeste do país, protestaram exigindo segurança contra os constantes assaltos que sofrem durante o trabalho - pelos quais não recebem qualquer compensação das empresas" ${ }^{17}$.

Além de um cenário de movimentações que já estava em crescimento, os tempos de pandemia trouxeram maior visibilidade a este tipo de trabalho ao redor do globo. A garantia das regras de distanciamento social está diretamente relacionada aos serviços de entrega realizados por estes trabalhadores, incluídos nos "serviços essenciais"18. O novo coronavírus exacerbou a "subsunção" destes trabalhadores à realidade do controle destas plataformas.

No Reino Unido e no México, a Uber anunciou o pagamento de um rendimento mínimo por até 14 dias àqueles motoristas que tiveram de parar de trabalhar ${ }^{19}$. $\mathrm{O}$ valor deste pagamento, no entanto, não garante a possibilidade de "ficar em casa", o que faz com que mesmo trabalhadores adoecidos continuem trabalhando ${ }^{20}$. Movimentos por melhores condições de trabalho se espalharam por toda Argentina, ao longo do último mês de maio, com a formação de duas assembleias nacionais de trabalhadores de entrega e reunião com o Ministério do Trabalho no país. A Agrupación de Trabajadores de Reparto (ATR) e os Glovers Unidos Argentina organizaram paralisações contra a precarização laboral ${ }^{21}$.

No cenário brasileiro, o número de mais de 38 milhões de trabalhadores informais e os dois dígitos da taxa de desemprego ${ }^{22}$, próxima dos $12 \%$, são índices que precederam a pandemia, mas aumentaram ainda mais durante essa crise sanitária. Na impossibilidade de achar emprego, a inserção individual no mercado de trabalho é colocada como a única saída. Os trabalhadores veem nas empresas-aplicativo a forma de inserção econômica mais rápida e acessível, o que cumpre a urgência da sobrevivência.

Já foi registrado que as inscrições para realizar entregas por aplicativos dobraram depois do início da quarentena. O número de entregadores que atendem a supermercados cresceu cinco vezes e algumas plataformas ampliaram seus serviços, incluindo atendimento a farmácias, lojas de conveniência e pet shops. Apenas o aplicativo iFood, de acordo com a reportagem da revista Veja, "recebeu em março 175 mil inscrições de candidatos interessados em atuar como entregadores na plataforma", o dobro das inscrições se comparado às recebidas no mês de fevereiro ${ }^{23}$.

É importante ressaltar que as empresas-aplicativo mantêm a privacidade de todos os seus números e não há qualquer obrigatoriedade de transparência sobre estas informações ou sobre como são processadas. Nesse sentido, a caracterização de um cenário do trabalho por plataformas digitais é prejudicada e torna-se pouco acurada. Alguns elementos, no entanto, podem ser apontados a partir de estudos recentes que buscam inferir dados e delimitar uma caracterização para este tipo de trabalho.

De acordo com o relatório "Digital labour platforms and the future of work: towards a decent work in the online world”, da Organização Internacional do Trabalho (OIT) $)^{24}$, o trabalho por plataformas digitais é um fenômeno tipicamente urbano: quatro de cada cinco trabalhadores de plataformas digitais encontram-se nas cidades. Também de acordo com o mesmo relatório, na América Latina, o Brasil tem importante representatividade no número total destes trabalhadores.

Ainda de acordo com o mesmo relatório da $\mathrm{OIT}^{24}$, os trabalhadores destas plataformas são em sua grande maioria homens jovens adultos, entre seus 25 e 40 anos. Em uma comparação ao redor do mundo, menos de $20 \%$ destes trabalhadores não cursaram o ensino médio, o que indica um nível médio de acesso à educação. No entanto, esses dados não estão abertos por região ou país, o que dificulta uma caracterização mais acurada da faixa etária e do nível educacional desses trabalhadores na realidade brasileira.

A pesquisa conduzida pelo Instituto Locomotiva sobre a economia dos aplicativos, e publicada no jornal $O$ Estado de S. Paulo ${ }^{25}$, em abril de 2019, indica que 4 milhões de trabalhadores autônomos se utilizam de plataformas digitais, como Uber, Rappi, 99 e iFood, para obtenção de suas rendas. Juntas, as empresas-aplicativos podem ser consideradas as maiores empregadoras do país. Mas a amplitude deste número de trabalhadores pode ser ainda maior, já que o estudo aponta também para o número de 17 milhões de trabalhadores autônomos e profissionais liberais que se utilizam de forma regular de aplicativos para complemento de renda ${ }^{25}$. Essa pesquisa demonstra a dimensão da uberização no Brasil, e aponta que se trata de um problema de multidão.

Nessa mesma pesquisa ${ }^{25}$, tem-se a divisão dos trabalhadores que se utilizam de aplicativos para trabalhar por região geográfica. O Sudeste brasileiro é a residência para quase a metade do número de trabalhadores de plataformas digitais. O Nordeste surge em segundo lugar nesta divisão, com quase um quarto dos trabalhadores por plataformas digitais trabalhando na região. O Centro-Oeste e Norte do país, juntos, representam quase $15 \%$ desses trabalhadores; e o Sul, por sua vez, representa $16 \%$. Ainda, é indicado que estes trabalhadores pertenceriam em 
sua maioria à classe $\mathrm{C}$. O que quer dizer que a renda média domiciliar desses trabalhadores está entre 2 mil e 3 mil reais ${ }^{26}$.

\section{Aprofundamentos da uberização durante a pandemia}

Já mencionamos que as transformações nas relações de trabalho e a sua precarização são um processo de décadas ao redor do globo. No Brasil, a intensidade dessa precarização ganhou fôlego renovado a partir da reforma trabalhista de 2017. As instâncias superiores da Justiça do Trabalho demonstram essa intensidade de reformulação de seus próprios princípios, abandonando a valorização do emprego, a igualdade em sentido material e a segurança jurídica.

Em agosto de 2018, o Tribunal Regional do Trabalho da $2^{\text {a }}$ Região (TRT-2), São Paulo, reconheceu em decisão inédita o vínculo de emprego entre um motorista e a $\mathrm{Uber}^{27}$. A decisão indicava que não há verdadeira autonomia do motorista em relação à empresa-aplicativo e que o trabalhador é submetido a regras que caracterizam o vínculo de subordinação. A relatora, desembargadora Beatriz de Oliveira Lima, afirmou que não existe algo como a "escolha" do trabalhador em se manter "on-line" ou "off-line" para prestação do serviço. Lima considerou falacioso este argumento, já que, se esta "escolha” fosse apenas feita pelo trabalhador, a empresa-aplicativo correria o risco de não dispor de motoristas em determinados dias e horários para o atendimento aos usuários ${ }^{27}$.

Um ano e meio passados desta decisão, em Fevereiro de 2020, o Tribunal Superior do Trabalho (TST) derrubou esta decisão indicando que a Uber é apenas uma mediadora do serviço e que o vínculo empregatício não pode ser reconhecido. Para o TST, os motoristas têm autonomia para escolher se conectarem ou não à plataforma. A decisão indica que "critérios antigos” não são adequados para pensar as "novas" relações trabalhistas que surgem com aplicativos e plataformas ${ }^{28}$.

Este entendimento está presente não apenas nestas recentes decisões, mas também nas declarações da presidenta do TST dadas ao jornal Folha de S.Paulo ${ }^{29}$, quando eleita. Maria Cristina Peduzzi assinala que "vamos acabar qualquer dia desses não distinguindo mais segunda de domingo", o que "talvez" seja preferido pelo trabalhador. Para ela, diante da "Quarta Revolução Industrial” que vivemos, a reforma trabalhista foi "tímida” e a regulação de outras modalidades do trabalho é necessária. Peduzzi anuncia que "a perda de empregos tradicionais será compensada por novas modalidades de trabalho".

Por isto, o necessário a ser feito é requalificar os trabalhadores para as "novas realidades". No entanto, não tão "novas”, já que a própria Peduzzi indica que a reforma da legislação trabalhistas veio "colocar no mercado de trabalho categorias que estavam à margem”, isto é, já existiam mas não passavam pelo jugo do Estado, como por exemplo o trabalho intermitente. Na mesma entrevista, Peduzzi explica que a "precarização [nestas modalidades de trabalho] pode haver, sem dúvida”, mas é preciso que nos adaptemos às "novas realidades econômicas ${ }^{29}$. Esta entrevista repercute com maior intensidade nas últimas decisões que não reconhecem nenhuma obrigação por parte das empresas-aplicativo em relação aos seus entregadores durante a pandemia do novo coronavírus.

Em abril passado, uma liminar previu o pagamento de um salário mínimo aos entregadores diagnosticados, sob suspeita ou em grupo de risco do novo coronavírus. Por 48 horas, a decisão foi válida. No entanto, pelo ponto de vista da desembargadora Dóris Ribeiro Prina, do TRT-2, estes entregadores utilizam "livremente" o aplicativo, bem como se inscrevem de acordo com os seus interesses. Esses trabalhadores não podem ser considerados empregados das empresas-aplicativo, mas "usuários” dessas, nas palavras da desembargadora ${ }^{30}$.

Prina reforça em sua decisão que não se pode estar "apegado" a "modelos tradicionais" para pensar estas novas relações de trabalho. É importante ressaltar que a liminar derrubada previa não apenas o pagamento aos entregadores adoecidos, sob suspeita de contaminação ou em grupo de risco, mas também a obrigatoriedade da compra de equipamentos de proteção para os trabalhadores, como álcool em gel para uso diário e, ainda, a obrigatoriedade de disponibilizar espaços para a higienização de veículos, mochilas de entrega e capacetes ${ }^{30}$.

A regressividade da Justiça do Trabalho reforça aquilo que mencionamos: o liberalismo econômico é revigorado. E a ele junta-se o argumento da modernização das relações de trabalho. As "novas modalidades" não podem ser pensadas com os "antigos" parâmetros da formalidade. Mesmo quando o mundo é assolado por uma crise sanitária aguda, esta regressividade se aprofunda e persiste na ideia da liberdade econômica. Apesar do discurso de modernização, o que vemos é a regressão das relações de trabalho como reguladas na Constituição Liberal de $1891^{31}$.

\section{Uberização, organização do trabalho e saúde do trabalhador: aspectos a serem considerados}

Se compreendemos que a uberização é uma forma de organização do trabalho, a saúde do trabalhador será afetada diretamente por ela. Quando 
a organização do trabalho se altera, a relação saúde-doença no trabalho é também alterada. No processo de transformações profundas nos mundos do trabalho nestes últimos cinquenta anos, podemos afirmar que houve a reconfiguração e o "redesenho" do mapa de acidentes e adoecimento no trabalho. As "novas" modalidades de trabalho que surgem da fragmentação da cadeia produtiva viabilizam a superexploração do trabalhador, principalmente daqueles que estão nas pontas dessa cadeia, a partir de jornadas mais extensas, maior insegurança e vulnerabilidade ${ }^{32}$.

Para a análise da relação saúde-doença no trabalho uberizado, é preciso estarmos atentos ao que persiste em novos formatos, é necessário que voltemos nossa atenção ao que se renova. Particularmente, é preciso que pensemos estes aspectos renovados na realidade de pandemia, em que a demanda dos trabalhadores uberizados aumentou exponencialmente. Vejamos os aspectos que podem auxiliar esta análise.

A possibilidade do controle em detalhes de cada etapa do trabalho uberizado é a utilização do taylorismo em sua mais bem acabada versão. O tempo de cada processo está registrado no aplicativo. Pensemos nas mensagens e avisos que recebem os usuários: “seu Uber chegará em 5 minutos” ou "o seu pedido já saiu para a entrega”. Igualmente, estão registrados os detalhes de todos os movimentos necessários para realização de cada processo. Pensemos agora no mapa que se abre no aplicativo com o melhor caminho a ser percorrido e a hora prevista de chegada que considera o trânsito neste percurso. Os tempos e movimentos do início do século XX, são registrados no século XXI no aplicativo, e não mais nas "fichas de instrução" de Taylor ${ }^{33}$.

A grande novidade do controle do trabalho pela tecnologia das empresas-aplicativo é baseada no arcaísmo das fábricas de mais de um século atrás. Autores de diversas abordagens que se debruçam sobre a saúde mental relacionada ao trabalho, indicam os efeitos de um trabalho dominado e subordinado, em que os trabalhadores não conseguem exercer seus potenciais psíquicos ${ }^{34}$. Alguns dirão que haverá a eliminação da vida mental dos trabalhadores se esses forem submetidos ao controle taylorizado do trabalho ${ }^{35}$.

A exposição ao risco no ambiente de trabalho, discussão tão central na saúde do trabalhador, agora não está mais vinculada ao ambiente da empresa, mas ao ambiente e às ferramentas que o trabalhador uberizado possui, adquire ou aluga. Isto é, ao carro novo e à bicicleta em boas condições, todos os equipamentos de segurança individual e a manutenção destes veículos, ao celular ou ao computador que suportam as aplicações e que devem ter internet estável para o acesso às plataformas. As empresas-aplicativo não possuem um espaço determinado, não existe tal coisa como um "ambiente de trabalho" em que riscos possam ser mapeados e endereçados.

O fato de não termos a concretude do ambiente de trabalho e destas empresas manterem sigilo de seus dados, regras e processos, dificultam sobremaneira que os interessados na relação saúde-doença no trabalho consigam delinear diagnósticos mais precisos e ações junto a este determinado grupo de trabalhadores. Trata-se de tema urgente para os interessados na temática da Saúde do Trabalhador a necessidade de aproximação dos movimentos de representação coletiva dos trabalhadores uberizados.

Assim como os riscos de seu trabalho, o ritmo, a intensidade e a extensão da jornada passam também a ser preocupação única e exclusiva do trabalhador uberizado. Não à toa, Ludmila Abílio indica que a nomenclatura mais adequada para os trabalhadores uberizados seria o de "autogerentes subordinados"36. Isto é, estes trabalhadores não podem ser considerados como "empreendedores de si mesmo", pois não exercem nenhuma inovação ou criatividade em seus trabalhos, nem desenham um "plano de negócio" em que têm autonomia sobre os preços de seus serviços. São apenas gerentes de si mesmos que devem manejar suas metas e condições diárias de trabalho.

Esta "meta” diária, apesar de não mais imposta por uma empresa, é imposta pela sobrevivência e pela manutenção do trabalhador no próprio mercado de trabalho. O cálculo dessas metas deve ser feito tendo em vista todos os custos de manutenção para o trabalho e para a sobrevivência. Ou seja, o trabalhador deve se autogerenciar tendo em vista o quanto precisa trabalhar para que seja mantida sua inserção individual no mercado de trabalho.

Devemos ressaltar que essas metas ganham reforço positivo importante. É parte do trabalho uberizado, a gamificação. A gamificação é a utilização da lógica do jogo em diversos espaços, como na educação e no trabalho ${ }^{37}$. Não se trata de uma ideia recente, o jogo aplicado ao trabalho e jogado no trabalho pode ser considerado antigo. Mas esse processo ganha novos contornos na atualidade. As empresas aplicam os jogos para diminuir o tédio e monotonia do trabalho uberizado, para encorajar o trabalho não remunerado dos trabalhadores e consumidores, e para funcionar como um novo departamento de recursos humanos que simula funções, como treinamento e gestão da remuneração - outrora responsabilidades deste departamento ${ }^{37}$.

O engajamento subjetivo que a lógica do jogo propõe deve ser levado em consideração na análise do trabalho, especialmente, quando esta lógica leva à maior intensidade e extensão da jornada de trabalho. 
Pensemos na gamificação presente nas promoções feitas para que o trabalhador alcance determinado número de corridas ou entregas ao dia, tendo como recompensa um valor a mais em sua remuneração. $\mathrm{Ou}$ ainda, promoções vinculadas à quantidade de horas em que o trabalhador deve estar on-line em horários ou dias da semana específicos; à quantidade de cancelamentos efetivados pelo trabalhador; e à quantidade de viagens por hora concluídas no horário determinado pela empresa-aplicativo. Além disso, as promoções podem estar vinculadas a locais específicos, fazendo com que o trabalhador se dirija ao local determinado pela empresa ${ }^{38}$.

\section{Comentários finais}

Conforme apresentamos, a uberização do trabalho tem tido aprofundamentos nos tempos de pandemia em que vivemos. No Brasil, milhares de

\section{Referências}

1. Abílio LC. Uberização: do empreendedorismo para o autogerenciamento subordinado. Psicoperspectivas. 2019;18(3):41-51. doi: 10.5027/ psicoperspectivas-vol18-issue3-fulltext-1674

2. Sato L. Diferentes faces do trabalho no contexto urbano. In: Coutinho MC, Bernardo MH, Sato L, organizadores. Psicologia social do trabalho. Petrópolis: Vozes, 2017. p. 151-74.

3. Araújo AJDS. Paradoxos da modernização: terceirização e segurança em uma refinaria de petróleo [tese]. Rio de Janeiro: Centro de Estudos em Saúde do Trabalhador e Ecologia Humana; 2001.

4. Cardoso A. A construção da sociedade do trabalho no Brasil. Rio de Janeiro: Editora FGV; 2015.

5. Cardoso A. Uma utopia brasileira: Vargas e a construção do estado de bem-estar numa sociedade estruturalmente desigual. Dados. 2010;53(4):775-819.

6. Santos WG. Cidadania e justiça: a política social na ordem brasileira. Rio de Janeiro: Campus; 1979.

7. Uchôa-de-Oliveira FM. Somos todos empreendedores? A demanda empreendedora como dispositivo de governo neoliberal [tese]. São Paulo: Universidade de São Paulo; 2020.

8. Conserva MDS, Araújo AJDS. Informalidade e precarização nos mundos do trabalho. Teoria Política e Sociedade. 2008;1(1):75-91.

9. Slee T. Uberização: a nova onda do trabalho precarizado. São Paulo: Elefante; 2018.

10. Krein JD, Abílio L, Freitas P, Borsari P, Cruz R. Flexibilização das relações de trabalho: insegurança para os trabalhadores. Revista do Tribunal Regional do Trabalho da $15^{\mathrm{a}}$ Região. 2018;(52):41-66. trabalhadores que perderam seus empregos antes e durante a crise sanitária transformam-se em "parceiros" das empresas-aplicativo pela urgência de sobreviver ou de complementar suas rendas, cortadas em mais de $50 \%{ }^{39}$.

Aqueles que estudam a saúde do trabalhador devem se debruçar sobre o tema tendo em vista a dimensão e os impactos dessa organização do trabalho nos trabalhadores. Faz-se urgente que a Saúde do Trabalhador resgate as formas de coletivizar o pensamento sobre o trabalho junto aos trabalhadores. É preciso que estejamos atentos às mobilizações dos trabalhadores uberizados, especialmente neste tempo em que o distanciamento social se impõe.

Torna-se crucial que os estudiosos do trabalho contribuam com a compreensão desta temática, identificando e registrando os impactos psicossociais dessas novas modalidades e as possibilidades de resistência e de organização coletiva das massas de trabalhadores uberizados.

11. Antunes R. O caráter polissêmico e multifacetado do mundo do trabalho. Trabalho, Educação e Saúde. 2003;1(2):229-37.

12. Marques L, Henrique A, Teixeira D, Abílio L. Informalidade: realidades e possibilidades para o mercado de trabalho brasileiro. São Paulo: Fundação Perseu Abramo; 2018.

13. Abílio L. Uberização do trabalho: a subsunção real da viração. Blog da Boitempo [Internet]. 22 fev 2017 [citado em $1^{\circ}$ maio 2020]. Disponível em: https://blogdaboitempo.com.br/2017/02/22/ uberizacao-do-trabalho-subsuncao-real-da-viracao/

14. Greve do Uber na França complica acesso aos aeroportos de Paris. Rádio França Internacional [Internet]. $18 \mathrm{dez} 2015$ [citado em $1^{\circ}$ maio 2020] Disponível em: http://www.rfi.fr/br/ franca/20151218-greve-do-uber-na-francacomplica-acesso-aos-aeroportos-de-paris

15. Dongel L. Os ‘precários digitais’ se organizam para defender seus direitos trabalhistas na Espanha. El País [Internet]. 28 dez 2017 [citado em $1^{\circ}$ maio 2020]. Disponível em: https://brasil.elpais.com/brasil/2017/12/01/ economia/1512138487_606849.html

16. Pereira F. Entregadores protestam contra redução de valor pago por aplicativos em SP. Uol [Internet]. $17 \mathrm{abr} 2020$ [citado em $1^{\circ}$ maio 2020]. Disponível em: https://noticias.uol.com.br/saude/ ultimas-noticias/redacao/2020/04/17/motoboysde-sp-protestam-contra-baixos-pagamentos-deaplicativos-de-entrega.htm?cmpid = copiaecola

17. Castanheira, T. Entregadores de aplicativos fazem greves por condições seguras no Brasil e no mundo. World Socialist Website [Internet]. 
25 abr 2020 [citado em 9 maio 2020]. Disponível em: https://www.wsws.org/pt/articles/2020/04/25/ braz-a25.html

18. Betim F. Quem faz a São Paulo que não pode parar por causa do coronavírus. El País [Internet]. 18 mar 2020 [citado em 9 maio 2020]. Recuperado de: https://brasil.elpais.com/sociedade/2020-0318/a-sao-paulo-que-nao-pode-parar-por-causa-docoronavirus.html

19. Uber vai pagar motorista que parar por coronavírus. Época Negócios. 8 mar 2020 [citado em $1^{\circ}$ maio 2020] Disponível em: https:// epocanegocios.globo.com/Empresa/noticia/2020/03/ uber-vai-pagar-motorista-que-parar-porcoronavirus-nos-eua.html

20. Nagesh A. The Uber driver evicted from home and left to die of coronavirus. BBC News [Internet]. 28 abr 2020 [citado em $9^{\circ}$ maio 2020]. Disponível em: https://www.bbc.com/news/uk-52413431

21. Martínez M. Cómo seguimos la lucha de los repartidores en Argentina y el mundo 2020. Prensa Obrera [Internet]. 13 maio 2020 [citado em 30 maio 2020]. Disponível em: https://prensaobrera.com/ sindicales/70162-como-seguimos-la-lucha-de-losrepartidores-en-argentina-y-el-mundo

22. Instituto Brasileiro de Geografia e Estatística. Pesquisa Nacional por Amostra de Domicílios: principais resultados: divulgação trimestral. Rio de Janeiro: IBGE; 2020.

23. Inscrições para realizar entregas por app dobraram depois da quarentena. Veja [Internet]. $1^{\circ}$ abr 2020 [citado em $1^{\circ}$ maio 2020]. Disponível em: https:// veja.abril.com.br/tecnologia/inscricoes-para-realizarentregas-por-app-dobraram-depois-da-quarentena/

24. International Labour Organization. Digital labour platforms and the future of work: towards decent work in the online world. Geneva: International Labour Office; 2018.

25. Gravas D. Aplicativos como Uber e iFood são fonte de renda de quase 4 milhões de autônomos. Locomotiva: Pesquisa \& Estratégia [Internet]. 28 abr 2019 [citado em 1 maio 2020]. Disponível em: https://www.ilocomotiva.com.br/singlepost/2019/04/29/ESTAD\%C3\%83O-Na-criseaplicativos-como-Uber-e-iFood-viram-maiorempregador-do-pa\%C3\%ADs

26. Associação Brasileira de Empresas de Pesquisa. Critérios Brasil. São Paulo: Abep; 2016.

27. TRT de São Paulo reconhece vínculo de emprego entre Uber e motorista. Conjur [Internet]. 27 ago 2018 [citado em $1^{\circ}$ maio 2020]. Disponível em: https:// www.conjur.com.br/2018-ago-27/trt-sao-pauloreconhece-vinculo-emprego-entre-uber-motorista

28. Valente F. Turma do TST nega vínculo de emprego entre Uber e motorista. Conjur [Internet]. $5 \mathrm{fev}$ 2020 [citado em 1 maio 2020]. Disponível em: https:/www.conjur.com.br/2020-fev-05/turma-tstnega-vinculo-emprego-entre-uber-motorista

29. Castanho W. 'Vamos acabar não distinguindo mais segunda de domingo', diz Maria Cristina Peduzzi. Folha de S.Paulo. $16 \mathrm{dez} 2019$ [citado em $1^{\circ}$ maio de 2020]. Disponível em: https://www1.folha. uol.com.br/mercado/2019/12/vamos-acabar-naodistinguindo-mais-segunda-de-domingo-diz-mariacristina-peduzzi.shtml

30. Netto PR. Desembargadora derruba liminar que obrigava iFood a pagar mínimo a entregadores. Estado de S. Paulo [Internet]. 8 abr 2020 [citado em $1^{\circ}$ maio 2020]. Disponível em: https://economia. uol.com.br/noticias/estadao-conteudo/2020/04/08/ desembargadora-derruba-liminar-queobrigava-ifood-a-pagar-minimo-a-entregadores. htm?cmpid = copiaecola

31. Delgado MG, Delgado GN. A reforma trabalhista no Brasil: com os comentários à Lei n. 13,467/2017. São Paulo: LTr; 2018.

32. Antunes R, Praun L. A sociedade dos adoecimentos no trabalho. Serviço Social \& Sociedade. 2015;(123):407-27.

33. Pinto, G. A. A organização do trabalho no século XX: taylorismo, fordismo e toyotismo. São Paulo: Expressão Popular; 2013.

34. Silva ES. Trabalho e desgaste mental: o direito de ser dono de si mesmo. São Paulo: Cortez; 2011.

35. Dejours C. A loucura do trabalho: estudo de psicopatologia do trabalho. São Paulo: Cortez; 1988.

36. Abílio LC. Uberização: a era do trabalhador just-intime? Estudos Avançados. 2020;34(98):111-26.

37. Mollick E, Werbach K. Gamification and the enterprise. In: Deterding S, Waltz S, organizadores. The gameful world: approaches, issues, applications. Cambridge, MA: MIT Pres; 2015; p. 439-58.

38. Uber. Como funcionam as promoções para os motoristas parceiros? [Internet]. Uber; 2020 [citado em $1^{\circ}$ maio 2020]. Disponível em https://help.uber. com/pt-BR/driving-and-delivering/article/comofuncionam-as-promo\%C3\%A7\%C3\%B5es-para-osmotoristas-parceiros?nodeId =2aa91e41-f139-4b4abfce-bf36c00ebc60

39. Brasil. Medida Provisória $n^{\circ}$ 936, de 1 de abril de 2020. Institui o Programa Emergencial de Manutenção do Emprego e da Renda e dispõe sobre medidas trabalhistas complementares para enfrentamento do estado de calamidade pública reconhecido pelo Decreto Legislativo $\mathrm{n}^{\circ} 6$, de 20 de março de 2020, e da emergência de saúde pública de importância internacional decorrente do coronavírus (covid-19), de que trata a Lei $\mathrm{n}^{\circ}$ 13.979, de 6 de fevereiro de 2020, e dá outras providências. Diário Oficial da União [Internet]. $1^{\circ}$ abr 2020 [citado em $1^{\circ}$ maio 2020]. Disponível em: http://www.planalto.gov.br/ccivil_03/_ato20192022/2020/mpv/mpv936.htm 